\title{
NARRATIVAS INTERATIVAS SOBRE O CUIDADO MATERNO E SEUS SENTIDOS AFETIVO-EMOCIONAIS
}

\author{
Tania Mara Granato* \\ Tânia Maria José Aiello-Vaisberg**
}

\section{Resumo}

$\mathrm{Na}$ medida em que a clínica e a pesquisa da maternidade reafirmam a importância do suporte social às mães, pretendemos investigar o imaginário de estudantes universitários sobre o cuidado materno. Partindo do pressuposto de que narramos para elaborar experiências vividas, reconhecemos no narrar um procedimento privilegiado de acesso aos sentidos afetivo-emocionais que subjazem a toda conduta humana. Elaboramos uma narrativa fictícia sobre o abandono materno para que estudantes de Educação Física e Jornalismo a completassem. Tais produçôes imaginativas, consideradas psicanaliticamente, apontam para uma abordagem ambígua. A mãe é responsabilizada pelo destino do filho, ainda que a compreensibilidade de sua conduta seja situada em termos do contexto social. Tal postura parece traduzir o contraste entre o pretendido tratamento ético da questão materna e as expectativas sociais em relação à figura materna, usualmente ocultas pelo discurso contemporâneo do politicamente correto.

Palavras-chave: maternidade; imaginário; narrativa; psicanálise.

\begin{abstract}
INTERACTIVE NARRATIVES ABOUT INFANT CARE AND ITS AFFECTIVE-EMOTIONAL MEANINGS

As the motherhood clinic and research reaffirms the importance of social support to mothers, we intend to investigate the imaginary of graduate students about

* Programa de pós-graduação da Faculdade de Psicologia da Pontifícia Universidade Católica de Campinas. São Paulo, Brasil. E-mail: taniagranato@uol.com.br.

** Instituto de Psicologia da Universidade de São Paulo, programa de pós-graduação da Faculdade de Psicologia da Pontifícia Universidade Católica de Campinas. São Paulo, Brasil. E-mail: aiello.vaisberg@gmail.com.
\end{abstract}


infant care. According to the assumption that we narrate to elaborate life experiences, we recognize that narration is a privileged procedure to access the underlying affective-emotional senses of any human conduct. We elaborated a fictional narrative about infant abandonment to be completed by students of Physical Education and Journalism. After psychoanalytical considerations, such imaginative productions suggest an ambiguous perspective. The mother is seen as responsible for the baby's destiny, despite the comprehensibility of her behavior, even if interpreted in terms of its social context. Such posture seems to translate the contrast between an ethical treatment of the maternal conflict and social expectations about maternal figure, usually hidden under the contemporary discourse of the politically correct.

Keywords: motherhood; imaginary; narrative; psychoanalysis.

\section{Resumen}

NarRativas interactivas SOBRE EL CUIDAdo Maternal y SUS SENTIDOS AFECTIVO-EMOCIONALES

En la medida en que la clinica y la investigación de la maternidad reafirman la importancia del apoyo social a las madres, tenemos la intención de investigar lo imaginario de los estudiantes universitarios sobre el cuidado maternal. Suponiendo que narramos para elaborar experiencias, reconocemos en el narrar un procedimiento privilegiado para favorecer el acceso a los significados afectivos y emocionales que subyacen a toda conducta humana. Desarrollamos un relato de ficción sobre el abandono infantil para que los estudiantes de Educación Física y Periodismo lo completasen. Tales producciones imaginativas, considerados psicoanaliticamente, indican un enfoque ambiguo. La madre es considerada responsable del destino de sus niños, aunque la comprensión de su conducta se encuentre en función del contexto social. Esta actitud parece reflejar el contraste entre el pretendido tratamiento ético de la cuestión maternal y las expectativas sociales en relación con la figura maternal, por lo general ocultas por el discurso contemporáneo politicamente correcto.

Palabras clave: maternidad; imaginación; narrativa; psicoanálisis.

\section{O narrar}

Desde a sua origem, a Psicanálise vem sendo construída a partir da clínica e suas narrativas, cujos exemplos clássicos são os estudos de caso e as vinhetas clínicas, em um movimento dialético entre a teoria e a prática psicanalíticas. Não é

Psic. Clin., Rio de Janeiro, vol. 25, N.I, P. I7 - 35, 2013 
raro que tais escritos sejam alvo de críticas quanto à sua fidedignidade, sobretudo no âmbito da pesquisa, embora a vertente psicanalítica defenda seu uso como instrumento legítimo e privilegiado de comunicação de vivências emocionais (Ogden, 2005a; Spence, 1994).

Em sua crítica aos fundamentos da Psicologia, Politzer (1928/1975) contrapôs a Psicanálise às viagens especulativas da Psicologia clássica e às mensurações reducionistas da Psicologia experimental como alternativa de ciência concreta, uma vez que opera a partir do drama vivido e narrado pelo indivíduo. Bleger (1963/1989) segue o caminho apontado por Politzer, sublinhando o aspecto afetivo-emocional da conduta humana como o recorte metodológico que define o campo da Psicologia. Enfatiza ainda que a apreciação rigorosa de qualquer conduta implica na consideração de seu contexto dramático, histórico e social, em um movimento interpretativo que produz um sentido que é, ao mesmo tempo, pessoal e coletivo.

Ao recusar o ideal positivista de objetividade em prol da perspectiva intersubjetiva (Stolorow, Atwood \& Orange, 2002), somos reconduzidos ao método associativo inaugurado pela psicanálise, bem como ao narrar como procedimento dialógico de aproximação da dramática humana.

Desde uma perspectiva que articula os campos da Filosofia e da Literatura, Benjamin (1936/1992) lança luz sobre a elaboração narrativa da experiência humana, ao abordar a narrativa que é tecida com o fio da vida pelas mãos habilidosas de um narrador-sensível que nos convida a viver uma experiência, emprestando sentido a um fato do cotidiano que nos interroga (Ricoeur, 1978/1999). Embora carregada de ensinamentos ancestrais, tal narrativa não se limita a eles, pelo contrário, abre-se para os múltiplos sentidos que se produzem no fértil campo da interlocução. Tais ideias se afinam com a proposta antropológica de Winnicott (1971/1994a) segundo a qual o homem como ser essencialmente criativo estabeleceria relaçôes autênticas com o mundo ao transitar pelo espaço potencial, espaço de interlocução inaugurado pela mãe que oferece ao seu bebê a oportunidade de criar/encontrar o mundo, produzindo o novo a partir da tradição.

Do ponto de vista das possibilidades de comunicação do encontro clínico, Ogden (2005a) argumenta que a realidade daquela experiência não poderá ser apreciada pelo leitor, a menos que os fatos clínicos sejam devidamente transformados em ficção. $\mathrm{Na}$ impossibilidade de testemunhar o encontro analítico, o leitor seria convidado a viver uma nova experiência, por meio da leitura do relato construído pelo analista-narrador:

[...] quando lemos um relato escrito de uma experiência com um paciente, o que estamos lendo não é a experiência em si, mas a criação de uma nova 
experiência (literária) pelo analista que (aparentemente) escreve a experiência que ele teve com o analisando (Ogden, 2005a, p.110).

Instigados pelo paradoxo apresentado por Ogden, (2005a) no que se refere à comunicação da "realidade" de um encontro pela via da ficção, recorremos ao escritor Lhosa (2006) quando aponta os elementos que comporiam um bom romance à guisa de orientação a jovens escritores. Segundo Lhosa, para que uma história seja persuasiva, isto é, para que convença o leitor de sua realidade, é necessário que parta de experiências vividas pelo próprio escritor. Inicialmente ancorada na realidade, a narrativa poderá vir a abandoná-la rumo a mundos fantásticos, à medida que a trama se desenvolve, sem que se corra o risco de perda da credibilidade da história.

Tanto o romance (Lhosa, 2006) como o escrito psicanalítico (Ogden, 2005a) partem do drama humano e ganham a confiança do leitor sem jamais abandonar a matéria-prima da qual são feitos - a vida. Longe da utopia do retrato fiel, a narrativa que se pretende rigorosa na comunicação de uma experiência humana mantém sua afinação com as muitas vozes que a compóem, afastando-se definitivamente do devaneio de uma Psicologia que Politzer (1928/1975) tanto criticava.

Se somos capturados por histórias que nos convidam a viver uma experiência através de seus personagens, preenchendo desse modo critérios de verdade quanto à realidade das emoçóes ali vividas, não nos parece leviano afirmar que a narrativa de um indivíduo é o que temos de mais palpável em termos do drama por ele vivido.

Partindo do pressuposto de que o homem narra em busca de reconhecimento de si, compreensão e orientação para a vida (Ricoeur, 1978/1999), reconhecemos o narrar como um procedimento privilegiado de acesso aos múltiplos sentidos afetivo-emocionais (Kohn, 2008) que se revelam não apenas na vida e na clínica, mas também no âmbito da pesquisa. As narrativas, aqui tomadas como trabalho psicológico sobre a matéria-prima do viver (Ogden, 2005b), serão consideradas não apenas como expressão de um indivíduo mas, parafraseando Politzer (1928/1975), como o próprio eu em ato.

A clínica winnicottiana da maternidade (Granato \& Aiello-Vaisberg, 2009), cujo enfoque visa facilitar que a mulher desenvolva o seu próprio estilo de ser mãe, tem nos informado sobre a insuficiência do suporte social àquelas que se dedicam à tarefa materna. A despeito das queixas maternas, o cuidado infantil continua a ser visto como preocupação e responsabilidade da mulher, inclusive pelos profissionais que dela se ocupam, como apontam os resultados de pesqui-

Psic. Clin., Rio de Janeiro, vol. 25, N.I, P. I7 - 35, 2013 
sa recente sobre o imaginário de enfermeiras obstétricas (Granato, Tachibana \& Aiello-Vaisberg, 2011), no sentido da idealização da maternidade e fascinação pelo bebê recém-nascido. Tais fatores se mostraram relevantes para a compreensão da dificuldade manifesta dessas profissionais em acolherem a ambivalência materna, frequentemente expressa pelas parturientes daquele hospital.

A partir dessa dupla perspectiva acerca da maternidade - clínica e investigativa - interrogamo-nos sobre o imaginário de jovens universitários que ainda se preparam para a parentalidade e para o exercício profissional, em termos da prática futura que emergirá, para além do domínio técnico, dos campos de sentido afetivo-emocional que sustentam nossas condutas.

\section{Estratégias metodológicas}

Tomar as teorias como metáforas a serem substituídas (Spence, 2001), paralelamente ao uso de um método que faça jus a um objeto de estudo tão complexo quanto a vida afetiva do homem, parece-nos ser o caminho mais profícuo para a compreensão ou explicação crítica da realidade, objetivo último da ciência (Furlan, 2008).

O método psicanalítico propõe que a busca dos sentidos afetivo-emocionais que fundamentam qualquer conduta humana se dê por meio da atenção flutuante do analista combinada à regra fundamental da Psicanálise, segundo a qual recomenda-se que o paciente associe livremente. Concebida por Freud como procedimento facilitador da emergência de conteúdos inconscientes da psique, a associação livre é definida por Laplanche e Pontalis (1982/1998) como:

Regra que estrutura a situação analítica. $\mathrm{O}$ analisando é convidado a dizer o que pensa e sente sem nada escolher e sem nada omitir do que lhe vem ao espírito, ainda que lhe pareça desagradável de comunicar, ridículo, desprovido de interesse ou despropositado (Laplanche \& Pontalis, p. 438).

A superação da noção de inconsciente como reservatório secreto de desejos reprimidos, juntamente com a meta psicanalítica que lhe é consequente, aquela que se refere a trazer tal conteúdo reprimido de volta à consciência, leva-nos à concepção mais fluida do inconsciente como a configuração que se produz no próprio ato de atribuir sentido a uma experiência vivida. Posiçáo que marca a condição criativa do homem (Winnicott, 1971/1994c) e a mobilidade dos sentidos, sejam eles conscientes ou inconscientes, retomando o 
método psicanalítico como desencadeador da mudança psíquica. Essa escolha que se funda na valorização do método, cuidando em discriminá-lo das teorias que inspira, libera o pesquisador da adesão acrítica a qualquer uma das escolas psicanalíticas (Herrmann, 2004b), permitindo que se beneficie do potencial heurístico de um proceder que, ao privilegiar o gesto espontâneo (Winnicott, 1971/1994b), aproxima-nos do viver concreto (Aiello-Vaisberg \& Machado, 2008).

Como contraponto necessário aos movimentos associativos do participante, a escuta psicanalítica, que é associativa e interpretativa (Wildlöcher, 2010), permite ao pesquisador vislumbrar os sentidos afetivo-emocionais que animam os relatos dos participantes, trazendo para o campo da pesquisa conhecimentos antes circunscritos ao espaço da clínica.

Considerando que a pessoalidade do pesquisador participa da produçấo dos dados de sua pesquisa, propomos a co-construção de uma história fictícia doravante denominadas narrativas interativas, aqui compreendidas como produção imaginativa que emerge da interação dos campos de sentido afetivo-emocional do pesquisador e do pesquisado (Granato, Corbett \& Aiello-Vaisberg, 2011), à semelhança do jogo do rabisco winnicottiano (Winnicott,1964/1989) e sua qualidade dialógica.

É nesse esforço associativo, no sentido da produção de um conhecimento que se assente sobre a dramática humana, que temos nos dedicado à investigação dos campos de sentidos afetivo-emocionais que fundamentam toda e qualquer conduta humana. Do campo do inconsciente freudiano rumamos pelo campo psicológico de Bleger (1963/1989) e chegamos com Herrmann (2004a) aos campos de sentidos afetivo-emocionais, compreendidos como enredos dramáticos sobre os quais se desenvolvem as açôes humanas.

A título de ilustração podemos pensar que um indivíduo que estivesse preso a uma trama imaginativa paranoide seria beneficiado, assim como aqueles com quem convive, se tivesse esse campo de sentidos modificado por uma perspectiva mais integrada. A transformação de um campo de preconceito para um campo de tolerância à diferença é outro exemplo do que pode ser buscado em termos de transformação de condutas pessoais e sociais. Vale ressaltar que a coexistência de campos contraditórios pode fundamentar tanto um conflito pessoal quanto atitudes politicamente corretas como expressão de um falso self (Winnicott, 1960/2003) que se submete às demandas sociais.

A identificação de campos de sentido afetivo-emocional tem se mostrado profícua, permitindo o acesso a redes motivacionais de conduta, como é o caso dos estudos sobre o imaginário que se traduz em posturas de profissionais diante

Psic. Clin., Rio de Janeiro, vol. 25, N.I, P. I7 - 35, 2013 
da maternidade (Granato, Tachibana \& Aiello-Vaisberg, 2011), além da captação dos momentos mutativos que marcam o progresso terapêutico (Granato \& Aiello-Vaisberg, 2011).

\section{Participantes}

Com o intuito de investigar produçôes imaginativas sobre o cuidado materno convidamos 60 estudantes universitários, sendo que 31 deles cursavam o $1^{\circ}$ ano do curso de Educação Física enquanto 29 eram alunos do $4^{\circ}$ ano de Jornalismo.

\section{Procedimento}

O procedimento foi realizado de maneira coletiva, no espaço de uma aula, abarcando dois momentos distintos: apresentação e completamento de uma narrativa interativa seguida de discussão em grupo.

Previamente elaborada por um dos pesquisadores, uma pequena história fictícia, cujos personagens expressavam conflitos na área da maternidade, foi distribuída em folha impressa para cada participante. Tal narrativa interativa foi lida em voz alta pelo pesquisador e interrompida quando a trama atingia seu clímax, momento em que os participantes foram convidados a completá-la de modo espontâneo, por escrito. Ao final, as histórias foram recolhidas e os participantes convidados a se manifestar sobre o procedimento, a trama, o tema veiculado pela história, ou qualquer outro assunto que lhes viesse à mente.

A interlocuçáo sobre a qual repousa o procedimento das narrativas interativas se inicia com a construção da narrativa fictícia, segue com a apresentação pessoal da história, acompanha a elaboração de cada participante, para se encerrar com a análise coletiva das narrativas, no contexto do grupo de pesquisa.

\section{Análise das narrativas}

Não é raro que pesquisas psicanalíticas se ocupem da mera aplicação de teorias psicanalíticas a todo e qualquer material clínico, obturando a possibilidade de que novos sentidos surjam de um método que prima pela polifonia de sentidos (Wallerstein, 2009).

Por essa razão propomos que a análise das narrativas interativas siga a recomendação psicanalítica de espera, para que o sentido emerja do diálogo estabe- 
lecido entre pesquisador e pesquisado, quando se dispuseram a criar juntos uma história. Salientamos que assumir esta perspectiva nos restaura como pesquisadores-participantes do encontro intersubjetivo tomado como lócus privilegiado da pesquisa em Ciências Humanas.

Tomada como rabisco (Winnicott, 1964/1989) a narrativa do pesquisador visa delinear um campo em que o conflito materno se expresse sem, contudo, anunciar sua solução, deixando que o participante conduza a narrativa, de modo livre e associativo, em direção ao desfecho que julgar apropriado.

Ouvindo a música e não somente a letra dessas histórias interativas (Spence, 2003; Ogden, 2005a), pretendemos captar os campos dramáticos que sustentam a produção imaginativa dos participantes, em seu conjunto, segundo sua ressonância afetivo-emocional no grupo de pesquisa. Assim instaurado o diálogo imaginativo entre pesquisadores e participantes, a captaçáo de campos de sentidos afetivo-emocionais terá lugar, sendo aqui compreendida como o tratamento psicanalítico que daremos aos nossos dados.

\section{Cuidados éticos}

Este estudo é oriundo de pesquisa de pós-doutorado desenvolvida na Pontifícia Universidade Católica de Campinas, visando avaliar o potencial investigativo e terapêutico de narrativas interativas como procedimento de abordagem do imaginário coletivo sobre o cuidado materno. Trata-se de pesquisa aprovada pelo Comitê de Ética da universidade em questáo, sob protocolo de no 411/08, e financiada pela Fundação de Amparo à Pesquisa no Estado de São Paulo (FAPESP).

Tomamos o cuidado de explicitar e esclarecer aos participantes os objetivos da pesquisa, as etapas do procedimento, a qualidade voluntária de sua participação, assim como o Termo de Consentimento Esclarecido, o qual foi assinado por todos que optaram por colaborar com este estudo.

\section{Resultados}

Para adequar o grande volume de material associativo produzido, optamos por apresentar as produçóes de cada grupo de participantes em duas etapas. Iniciamos com a narrativa que foi lida pelo pesquisador, dando continuidade com as histórias dos participantes através de eixos dramáticos constituídos pela escuta psicanalítica.

Psic. Clin., Rio de Janeiro, vol. 25, N.I, P. I7 - 35, 2013 


\section{Narrativa do Pesquisador}

Interrogada pela polícia, Margarete afirmou que deu a filha recém-nascida a uma mulher que passava perto do matagal, onde acabara de dar à luz, negando a acusação de que teria abandonado o bebê no rio. Adalvino, roceiro que capinava nas proximidades, ouvindo o que lhe pareceu ser o miado de um gato, correu para a margem do rio. Boiando sobre as águas, um pedaço de madeira sustentava um saco plástico que se mexia. Cismado com os gemidos que dali vinham, Adalvino resolveu mergulhar, e quando alcançou a jangada improvisada viu que se tratava de um recém-nascido abandonado. Retirou-o da água, procurou um pano seco na carroça para enrolar o bebê e correu para o hospital mais próximo. O bebê sobreviveu e está em processo de adoção por um casal sem filhos, enquanto a mãe está presa, aguardando o julgamento. Diz ela que quando sair da prisão vai lutar para reaver a filha. Encafifado com o caso, Adalvino procurou várias pessoas para trocar ideias: o delegado, o padre, o doutor, o compadre e, por último, sua mulher. $\mathrm{O}$ delegado, já devidamente informado pelo psiquiatra da cidade, disse que a suspeita era louca, carecia de confiança e que não deveria em hipótese alguma ficar com a criança. $O$ padre, que também não era bobo, aconselhou que se tentasse compreender os motivos que levaram a pobre infeliz a cometer tal ato, mas sugeriu que fosse avaliada por especialistas antes que se lhe pusesse um bebê nos braços de novo. O doutor, simpatizante das causas perdidas, argumentou que se a doente fosse acompanhada por um psicólogo, um psiquiatra e uma assistente social poderia desempenhar suas funçôes de mãe com tranquilidade. Já o compadre foi curto e afiado, como só um compadre pode ser: - Amigo velho, isso aí não presta não, ou é coisa do capeta ou a mulher é a reencarnação da mula-sem-cabeça. - A última a dar sua opiniáo foi a mulher de Adalvino que pensou, pensou e concluiu que o marido só descobriria a verdade se fosse conversar pessoalmente com a dita cuja. E foi isso que Adalvino fez...

\section{Narrativas dos participantes do grupo de estudantes de Educação Física}

Partindo da escuta diferenciada do pesquisador-psicanalista chegamos a observaçōes que nos pareceram qualitativamente relevantes, seja por sua frequência e/ou intensidade, seja por seu caráter peculiar e/ou inusitado, uma vez que 
foram selecionadas em termos do impacto do conjunto das histórias sobre os pesquisadores de nosso grupo:

- Envolvimento afetivo com a trama: os participantes se apropriam da história de Margarete de modo pessoal, a partir do ponto em que o pesquisador a interrompe, reconduzindo seus personagens em direção a um destino próprio.

- Identificaçáo com os personagens: observamos que grande parte dos participantes se identifica com o personagem-camponês que, além de salvar a criança do abandono, é levado a atribuir um sentido à história, deixada em aberto pelo pesquisador, finalizando-a com uma solução para o conflito. Embora tenha sido caracterizado como um personagem bondoso, ao final da história o camponês não só julga como também emite uma sentença em relação à conduta materna e ao destino da criança abandonada.

- Reação ao desamparo: notamos que, em muitas histórias, a indignação el ou a compaixão do participante frente ao recém-nascido desamparado norteiam os acontecimentos subsequentes, assim como seu desfecho.

- Compreensibilidade da atitude materna: embora grande parte das histórias elabore motivos para o abandono materno, nem sempre o destino da personagem-mãe é modulado pelas motivaçóes sugeridas, sendo rara a clemência do autor, que termina por julgar e punir. Naqueles casos em que a conduta materna é compreendida, não chega a ser aceita como humana.

- Crime sem perdão: o crime de abandono é, na maior parte das narrativas, explícita ou implicitamente declarado como imperdoável, ainda que o autor atribua a conduta materna à pobreza, ao abandono do parceiro e/ou da família, ou ainda a problemas mentais. Um prejulgamento da personagem perpassa as histórias que a punem com mais rigor, tornando seus motivos irrelevantes quanto ao destino final.

- Abandono como proteção à criança: outro elemento relevante foi o fato de alguns participantes interpretarem o ato do abandono como o modo que a mãe encontrou para proteger o recém-nascido das adversidades a que ele estaria exposto, caso fosse mantido em sua companhia. Ainda aqui o crime é visto como imperdoável.

- Direitos maternos sobre a criança: outro desfecho frequente faz referência à mãe que perde seus direitos sobre a criança abandonada, de quem é separada por incapacidade materna, por isolamento prisional, ou

Psic. Clin., Rio de Janeiro, vol. 25, N.I, P. I7 - 35, 2013 
ainda pelo fato de a criança ter sido adotada. Duas histórias fazem exceção a essa regra: em uma delas a mãe é estimulada pelo personagem camponês a reaver sua filha e, em outra, o mesmo oferece-lhe abrigo.

- Referência ao pai da criança: outro elemento que se destacou como pano de fundo desse grupo de histórias referiu-se à quase total ausência da figura paterna. Nas poucas vezes em que o pai é referido, surge como figura hostil ou negligente, porém nunca considerado responsável. Há apenas um caso em que o pai é responsabilizado pelo crime, porém escapa da justiça e permanece foragido, após ter matado a esposa na delegacia.

\section{Narrativas dos participantes do grupo de estudantes de Jornalismo}

- Envolvimento com a trama: todos os participantes partem do momento em que o camponês decide ir ao encontro da máe que está sendo acusada de abandono, capturados pela trama. Enveredando pelos conflitos apresentados pela dupla de protagonistas, cada participante delimita um campo de sentidos sobre o qual a história se sustenta e tem seu fim justificado.

- Identificação com os personagens: os participantes se identificam com o camponês e suas dúvidas a respeito do que levou a jovem máe a abandonar seu bebê recém-nascido. Generoso e compreensivo, o camponês se sensibiliza pelo drama vivido pela personagem-mãe, apesar de tocado pelo desamparo do bebê.

- Mãe como vítima: muitas histórias trazem o desespero de uma mulher vitimada por problemas sociais, tais como a pobreza, o abandono familiar, abuso infantil ou estupro. Em alguns relatos o desespero tem mais afinidades com a loucura ou com estados psicológicos alterados, ainda que momentâneos. Outros fazem menção ao arrependimento materno e muito poucos falam de crueldade, sendo que um único participante se refere à "sem-vergonhice" da personagem-mãe, sugerindo que as "incompetentes" para a maternidade sejam esterilizadas.

- Abandono e adoção: em algumas histórias o abandono é entrevisto pela personagem-máe como soluçáo para os problemas futuros da criança, enquanto a adoção do bebê abandonado é interpretada pela maioria dos participantes como a melhor solução para o conflito apresentado. 
- Direitos maternos sobre a criança: na maior parte das histórias a mãe que abandona permanece separada de seu filho, seja por incapacidade, doença, pobreza ou falta de suporte social. Em apenas duas narrativas surge a perspectiva de retomada da maternidade, em uma delas a mãe se submete a tratamento psiquiátrico e na outra recebe ajuda governamental.

- Compreensibilidade da atitude materna: observamos neste grupo uma atitude preponderante de compreensão e aceitação do drama materno, diferentemente das produçóes do primeiro grupo. Diante da acusada, o camponês se sensibiliza e compreende sua situação, abstendo-se de julgá-la, ou sugerir qualquer tipo de punição.

- Figura paterna: o pai do bebê abandonado é caracterizado por este grupo como ausente, negligente, confuso, estuprador, desconhecido ou ameaçador, sendo apontado como autor do abandono do filho em uma das narrativas.

\section{Discussão}

\section{Campos de sentidos afetivo-emocionais da Narrativa do Pesquisador}

Sabemos que a narrativa do pesquisador não é construída nem escolhida por acaso e que sua apresentaçáo ao participante da pesquisa provoca ou interroga certos campos da experiência humana. São recortes de vivências que emergem da vida profissional e pessoal do pesquisador, ou do grupo de pesquisadores, e que convidam o participante a se posicionar frente ao drama narrado, agregando sua contribuição pessoal.

No que se refere à história de Margarete, o primeiro parágrafo traz o tema do abandono do recém-nascido descontextualizado do drama vivido pela mãe, a fim de abrir a narrativa para a elaboração imaginativa dos participantes. O relato segue para o salvamento do bebê, introduzindo o leitor no conflito que se apossa do personagem do roceiro. No segundo e último parágrafo este parte em busca da explicação que dará sentido à conduta materna, consultando algumas figuras institucionais, como a polícia, a igreja, a ciência e a crença popular, as quais emitem seus pareceres. É a esposa do roceiro, como segunda personagem feminina e última a ser consultada, que sugere o encontro de Adalvino com a acusada a fim de conhecer seus argumentos e aliviar a angústia da

Psic. Clin., Rio de Janeiro, vol. 25, N.I, P. I7 - 35, 2013 
falta de sentido. Neste ponto o participante é instado a continuar a história, já devidamente capturado pelo drama do bebê abandonado e pelo conflito moral do roceiro, elaborando o campo de sentidos que sustentará a narrativa até o seu desfecho.

Os campos da experiência humana insinuados por essa história fazem referência à possibilidade de que a mãe não deseje cuidar de seu bebê (Badinter, 2010), bem como às reaçóes que se erguem frente à precariedade humana, expressa pelo desamparo do recém-nascido, da mãe frente ao seu drama, além da busca da verdade/sentido empreendida pelo camponês.

Quanto à escolha pela história de Margarete, dentre outras elaboradas para o mesmo fim, levantamos duas hipóteses principais: o pesquisador estaria se interrogando sobre o modo como o profissional de Educação Física lida com conflitos emocionais na área da maternidade, habituado que está ao enfoque corporal em sua prática, enquanto a produção do grupo de futuros jornalistas interessar-lhe-ia em função da alegada influência que a mídia tem sobre a conduta das pessoas, determinando valores, posturas e açóes.

\section{Campos de sentidos afetivo-emocionais das Narrativas dos Participantes}

O envolvimento afetivo com a história narrada e a riqueza das produções imaginativas (Aiello-Vaisberg \& Machado, 2008) dos grupos pesquisados sugerem a potencialidade do procedimento das narrativas interativas na investigação das bases afetivo-emocionais de condutas frente ao cuidado materno. Tal constatação se reveste de importância no âmbito da pesquisa em Psicologia pelo fato de permitir ao profissional de saúde interrogar e integrar os aspectos afetivo-emocionais, sociais e éticos de suas práticas, possibilitando o seu aprimoramento profissional.

Tomaremos as narrativas produzidas pelos participantes desta pesquisa como elaboraçóes imaginativas que emergem de um coletivo e se organizam narrativamente a fim de dar sentido e solução ao drama para o qual foram chamados a colaborar. Nomes foram atribuídos aos campos de sentidos, à semelhança de títulos de histórias que aludem e, de certa forma, condensam a trama que se desenrola ao longo do texto. Lembramos que como tais campos narrativos são sempre mutantes, em função dos estados de self que veiculam (Stern, 2009), serão considerados como expressões de um grupo em um dado momento, frente a um determinado conflito, permanecendo sempre abertos a novas configuraçóes. 


\section{Crime e Castigo}

O campo aqui denominado "Crime e Castigo" estende-se quase exclusivamente sob as produçóes do grupo 1 (Educação Física) comunicando-nos que, a despeito dos motivos que uma mãe possa ter para abandonar seu bebê, tal ato será sempre considerado crime e, como tal, demandará uma puniçấo. Independentemente das condiçóes físicas, psicológicas e socioeconômicas da mãe, recairá unicamente sobre ela a sentença que, visando vingar o abandono da criança, abandona a mãe à própria sorte, enquanto o pai é mantido à margem de todo o processo, quase isento de suas obrigaçôes paternas (Giordano, 2007).

Parece-nos razoável supor que o personagem do camponês que salva o bebê, investiga o crime, julga a mãe e profere sua sentença figure para esse grupo como uma figura paterna alternativa, revestida do poder, responsabilidade e rigor que faltam à figura apagada do pai biológico. Como uma das participantes notou durante o momento de reflexáo que se seguiu à escrita das narrativas, antes que um movimento de compreensão da conduta materna tivesse lugar, os participantes-autores procederam ao julgamento do caso, comprometendo qualquer tentativa ulterior de aproximação do drama comunicado pela personagem-mãe.

Levantamos a hipótese de que o clima da narrativa do pesquisador pudesse estar conduzindo as histórias no sentido do julgamento da atitude materna, não deixando margem para a criação própria dos participantes. Porém abandonamos tal suposição ao nos debruçarmos sobre as narrativas elaboradas pelo grupo 2 (Jornalismo), nas quais verificamos uma postura bastante diversa, ensejando a suposição de um campo de "Crime sem Castigo", ou mais apropriadamente de descriminalização. Essa nova perspectiva parece resultar da disposição para compreender a personagem-mãe como fio condutor da história, em substituição ao propósito de condená-la.

Resumo das características do campo "Crime e Castigo":

1. Clima policialesco

2. Ato transborda a possibilidade de compreensão

3. Abandono materno como ato desumano ou inumano

4. Crime hediondo seguido de justiça implacável

\section{Compromisso com a Verdade}

O campo "Compromisso com a Verdade" expressa a lógica afetivo-emocional que fundamenta a produção de duas narrativas do grupo 1 (Educação Física)

Psic. Clin., Rio de Janeiro, vol. 25, N.I, P. I7 - 35, 2013 
e todos os relatos do grupo 2 (Jornalismo), com exceçáo de um, revelando que a punição aqui não se coloca como prioridade. $\mathrm{O}$ esforço para compreender a conduta materna toma o lugar de sua condenação, neste segundo grupo, sinalizando um cuidado ético que o mantém afastado dos pré-julgamentos. Bastante afinado com um dos lemas do Jornalismo - o compromisso com a verdade - esse grupo de narrativas traz o camponês como figura sensível e esclarecida quanto à contextualização do fenômeno, principalmente em seu aspecto social. Em oposição ao clima emocional das histórias do grupo 1, o drama materno é circunscrito por um campo mais racional nos relatos do grupo 2, nos quais o camponês é poupado de sentimentos de revolta e indignação, e o pai é incluído como corresponsável pelo abandono. A serenidade com que o assunto é tratado não parece significar neutralidade ou frieza, uma vez que alguns relatos revelaram grande intensidade emocional, como em histórias que versaram sobre abuso sexual, estupro ou possessão demoníaca da personagem-mãe. Do mesmo modo o sentimentalismo parece não ter lugar aqui, pois, apesar da abertura ao sofrimento materno, os participantes entendem a adoção como a melhor saída para a criança, revelando o tratamento ético para com todos os personagens.

É possível relacionar essa apreensão mais ampla e menos impulsiva do fenômeno em questão com a maturidade atingida por estudantes em final de curso, como era o caso dos alunos de Jornalismo, embora possamos também supor diferenças significativas entre as duas formaçóes acadêmicas, bem como em relação à maneira de ser e ver o mundo daqueles que escolhem uma carreira ou outra.

\section{Resumo das características do campo "Compromisso com a Verdade"}

- Clima de investigação jornalística

- A verdade como foco norteador

- Determinação social da conduta materna

- Tratamento ético do dilema materno

\section{Consideraçóes finais}

Considerando as produçóes do grupo 1 em relação ao contexto histórico-social contemporâneo, no qual a igualdade de direitos e deveres entre homens e mulheres figura como conquista adquirida, surpreendemo-nos com o fato de que jovens universitários brasileiros ainda esperem das mães uma dedicação incon- 
dicional à tarefa materna, responsabilizando-a pelo bem estar físico e mental da prole. Badinter (1980/1985) é uma das autoras que critica a Psicanálise enquanto teorização que alimenta o sentimento de culpa materno, ao atribuir a saúde mental do adulto à relação primordial deste com sua mãe.

Para muitos de nossos participantes a mãe que se furta à maternidade é vista como louca, doente ou malvada. Porém, se aliarmos as produçôes imaginativas dos dois grupos de participantes deste estudo à experiência clínica com gestantes e mães (Granato, 2007; Granato \& Aiello-Vaisberg, 2008; Aiello-Vaisberg \& Granato, 2006), bem como aos estudos acima citados sobre o imaginário acerca da maternidade, teremos o seguinte panorama: para além dos quadros puerperais graves (Brockington, 2004) apontados por alguns dos participantes deste estudo, fatores de ordem afetivo-emocional, social, política e econômica apresentam-se como igualmente importantes na promoção e manutenção de uma relação parental sadia e responsável.

Cumpre salientar que o campo do "Crime e Castigo" não se expressa exclusivamente no grupo 1, na medida em que o abandono materno é unanimemente concebido como crime e, por essa mesma razão, parece supor um castigo. O que o campo "Em busca da Verdade" acrescenta ao conjunto de produçôes no qual a mãe é vista como única responsável (Giordano, 2007) é a formulação de um sentido que fundamenta a conduta de Margarete, humanizando-a - enfoque que atenua a rigidez moral, entrevista no primeiro grupo de narrativas, permitindo uma visão mais compreensiva e contextualizada da questão materna.

Considerando a fecundidade do procedimento das narrativas interativas na investigaçáo dos campos de sentidos, o envolvimento afetivo dos participantes com a trama e sua identificação com os personagens, admitimos como válida a hipótese de que o ato de narrar e o processo de elaboração psíquica guardem grande afinidade. $\mathrm{O}$ imaginar, o sonhar e o narrar delineiam os contornos de uma experiência que, de outra forma, permaneceria sem sentido, e consequentemente não-integrada, tornando-se indisponível para uso. A partir do contínuo movimento entre o que narramos e o que somos (Bruner, 2004), uma identidade narrativa (Ricoeur, 1990) se constitui, garantindo a continuidade de um self (Winnicott, 1945/1992) que se mantém enquanto se transforma ao longo da vida, em um movimento aparentemente paradoxal que abriga o mesmo e o diferente.

Embora usualmente o discurso científico se construa em oposição à sabedoria popular, perguntamo-nos se as narrativas não deitariam pontes entre esses dois saberes, oferecendo-se à gestante e à mãe como alternativa aos rituais de passagem primitivos (Van Gennep, 1908/1984), tendo em vista a insuficiência de

Psic. Clin., Rio de Janeiro, vol. 25, N.I, P. I7 - 35, 2013 
suporte social observada na contemporaneidade (Rochette, 2005). Nesse contexto de maternidade relegada à experiência solitária, as expectativas sociais de que a mulher concilie satisfatoriamente a carreira profissional à tarefa materna, além das exigências de uma sociedade cada vez mais preocupada com a forma física, o poder econômico e o sucesso fugaz, configuram-se como elementos adicionais de sobrecarga física e emocional.

\section{Referências}

Aiello-Vaisberg, T. M. J. \& Granato, T. M. M. (2006). Ser e Fazer na clinica winnicottiana da maternidade. Aparecida, SP: Idéias e Letras.

Aiello-Vaisberg, T. M. J. \& Machado, M.C.L. (2008). Pesquisa psicanalítica de imaginários coletivos à luz da teoria dos campos. In: J. Monzani \& L. R. Monzani (Orgs). Olhar: Fabio Herrmann - Uma viagem psicanalitica. (pp. 311-324). São Paulo: Pedro e João Eds/UFSCar.

Badinter, E. (1985). Um amor conquistado: o mito do amor materno. Rio de Janeiro: Nova Fronteira. (Trabalho original publicado em 1980)

Badinter, E. (2010). Le conflit: la femme et la mère. Paris: Flammarion.

Benjamin, W. (1992). O narrador: reflexôes sobre a obra de Nikolai Leskov. In: W. Benjamin. Sobre Arte, Técnica, Linguagem e Politica (pp. 27-57). Lisboa: Relógio D’Água. (Trabalho original publicado em 1936)

Bleger, J. (1989). Psicologia da conduta. Porto Alegre: Artes Médicas. (Trabalho original publicado em 1963)

Brockington, I. (2004). Postpartum psychiatric disorders. The Lancet, 363, 303-10.

Bruner, J. (2004). Life as narrative. Social Research, 71(3), 691-710.

Furlan, R. (2008). A questão do método na psicologia. Psicologia em Estudo, 13(1), 25-33.

Giordano, S. (2007). Crimes and misdemeanours: the case of child abandonment. Journal of Medical Ethics, 33(1), 28-34.

Granato, T. M. M. (2007). Modelo de Pesquisa em Psicologia da Saúde. In: F. F. Bortoletti, A. F. Moron J. B. Filho, M. U. Nakamura, R. M. Santana \& R. Mattar (org.). Psicologia na prática obstétrica: abordagem interdisciplinar (pp. 141-150). Sáo Paulo: Manole.

Granato, T. M. M. \& Aiello-Vaisberg, T. M. J. (2008). I was looking for a different treatment. Psychoanalytic Review, 95(4), 655- 667.

Granato, T. M. M. \& Aiello-Vaisberg, T. M. J. (2009). Maternidade e colapso: consultas terapêuticas na gestação e pós-parto. Paideia, 19(44), 395-401.

Granato, T. M. M. \& Aiello-Vaisberg, T. M. J. (2011). Uso terapêutico de narrativas interativas com mães em situação de precariedade social. Psico (PUCRS), 42(4), 494-502.

Psic. Clin., Rio de Janeiro, vol. 25, N.I, P. I7 - 35, 2013 


\section{4 - Narrativas interativas sobre o cuidado materno}

Granato, T. M. M., Corbett, E. \& Aiello-Vaisberg, T. M. J. (2011). Narrativa interativa e Psicanálise. Psicologia em Estudo, 16(1), 157-163.

Granato, T. M. M., Tachibana, M. \& Aiello-Vaisberg, T. M. J. (2011). Narrativas interativas na investigação do imaginário coletivo de enfermeiras obstétricas sobre o cuidado materno. Psicologia e Sociedade, 23(n.spe.), 81-89.

Herrmann, F. (2004a). Introdução à Teoria dos Campos. São Paulo: Casa do Psicólogo.

Herrmann, F. (2004b). O método da psicanálise. In: F. Herrmann. Introdução à Teoria dos Campos (pp. 51-65). São Paulo: Casa do Psicólogo.

Kohn, M. (2008). Je recite l'homme: du récit dans la psychanalyse. Cliniques méditerranéenne, 77, 205-214

Laplanche, J. \& Pontalis, J.-B. (1998). Vocabulário de psicanálise. São Paulo: Martins Fontes. (Trabalho original publicado em 1982)

Lhosa, M. V. (2006). Cartas a um jovem escritor. Rio de Janeiro: Elsevier.

Ogden, T. H. (2005a). On psychoanalytic writing. In: T. H. Ogden. This art of psychoanalysis: dreaming undreamt dreams and interrupted cries (pp. 109-123). London: Routledge.

Ogden, T. H. (2005b). This art of psychoanalysis: dreaming undreamt dreams and interrupted cries. In: T. H. Ogden. This art of psychoanalysis: dreaming undreamt dreams and interrupted cries (pp. 1-18). London: Routledge.

Politzer, G. (1975). Crítica dos fundamentos da psicologia. Lisboa: Editorial Presença. (Trabalho original publicado em 1928)

Ricoeur, P. (1990). Soi-même comme un autre. Paris: Seuil.

Ricoeur, P. (1999). Historia y narratividad. Barcelona: Paidós Ibérica. (Trabalho original publicado em 1978)

Rochette, J. (2005). Le temps du post-partum immédiat. Une clinique du "qui-vive" et de l'après-coup. Neuropsychiatrie de l'enfance et de l'adolescence, 53, 11-18.

Spence, D. P. (1994). The rhetorical voice of psychoanalysis: displacement of evidence by theory. USA: Harvard.

Spence, D. P. (2001). Case reports in a two-person world. Psychonalytic Psychology, 18(3), 451-467.

Spence, D. P. (2003). Listening for rethorical truth. Psychoanalytic Quarterly, 72(4), 875-903.

Stern, D. B. (2009). Partners in thought: a clinical process theory of narrative. Psychoanalytic Quarterly, 78(3), 701-731.

Stolorow, R. D., Atwood, G. E. \& Orange, D. M. (2002). Worlds of experience: interweaving philosophical and clinical dimensions in psychoanalysis. New York: Basic Books.

Van Gennep, A. (1984). The rites of passage. Chicago: University of Chicago. (Trabalho original publicado em 1908)

Wallerstein, R. S. (2009). What kind of research in psychoanalytic science? International Journal of Psychoanalysis, 90, 109-133.

Psic. Clin., Rio de Janeiro, vol. 25, N.I, P. I7 - 35, 2013 
Wildlöcher, D. (2010). Distinguishing psychoanalysis from psychotherapy. International Journal of Psychoanalysis, 91, 45-50.

Winnicott, D. W. (1989). The squiggle game. In C. Winnicott (org.). Psychoanalytic explorations (pp. 299-317). London: Karnac. (Trabalho original publicado em 1964)

Winnicott, D. W. (1992). Primitive emotional development. In: D. W. Winnicott. Through paediatrics to psycho-analysis: Collected Papers (pp. 145-156). Levittown, PA: Brunner \& Mazel. (Trabalho original publicado em 1945)

Winnicott, D. W. (1994a). Playing: a theoretical statement. In D. W. Winnicott. Playing and reality (pp. 38-52). London: Routledge. (Trabalho original publicado em 1971)

Winnicott, D. W. (1994b). Playing and reality. London: Routledge. (Trabalho original publicado em 1971)

Winnicott, D. W. (1994c). Playing: creative activity and the search for the self. In D. W. Winnicott. Playing and reality (pp. 53-64). London: Routledge. (Trabalho original publicado em 1971)

Winnicott, D. W. (2003). Ego distortion in terms of true and false self. In: D. W. Winnicott. The maturational processes and the facilitating environment (pp. 140-152). London: Karnac. (Trabalho original publicado em 1960)

Recebido em 12 de setembro de 2012 Aceito para publicação em 08 de janeiro de 2013 